\title{
Academics' Motivations in Professional Training Courses: Effects on Learning Engagement and Learning Gains
}

Professional training opportunities are crucial for university academics to expand their competencies and implement high quality educational practices. Within these opportunities, academics differ in the extent to which they engage in learning and their resulting learning gains. A theoretical explanation for these differences involves their motivations in the form of achievement goals. As such, in the current study we investigated the effects of academics' achievement goals on their learning engagement and learning gains in a professional training course. Forty-eight university academics completed assessments of achievement goals prior to course participation, their learning engagement throughout the course (three short assessments measuring: effort, learning intensity, risk-taking, elaboration, implementation, and persistence), and their learning gains after the course. Latent growth curve modeling revealed a significant influence of achievement goals on the overall levels of learning engagement. Specifically, learning approach goals led to more functional learning engagement while work avoidance goals led to less functional learning engagement. Further analyses attested that academics' achievement goals affected the amount they learned, mediated by their learning engagement. These findings highlight the importance of academics' achievement goals being supported that to ensure quality learning experiences.

Keywords: achievement goals; learning engagement; learning gains; university scholars; faculty; professional training 


\section{Introduction}

University academics need to constantly learn and improve throughout their career (e.g., Borko, 2004; van Eekelen, Boshuizen, \& Vermunt, 2005). Only through the professional development of competencies for teaching can they realize high-quality instruction and student learning (Biggs \& Tang, 2011; Mizell, 2010). While learning opportunities for academics include both informal and formal activities (Amundsen \& Wilson, 2012), especially the latter are important for academics who-unlike school teachers - often lack explicit didactical training and are frequently confronted with changing didactic requirements (Ates \& Brechelmacher, 2013).

Professional training courses are crucial for developing skills and improving teaching competences, however, some academics are more engaged and learn more than others (Ebert-May et al., 2011; Sunal et al., 2001). Understanding these differences is necessary for supporting effective learning of academics therein. In school settings, students who are more engaged in learning have been found to have higher academic achievement (e.g., Froiland \& Worrell, 2016; Pintrich \& de Groot, 1990).

Consequently, it can be assumed that academics who engage strongly in learning during professional training courses may benefit more from them. In their meta analysis on vocational learning, Colquitt, LePine, and Noe (2000) found that individual factors such as motivations play an important role in successful learning (see Bouwma-Gearhart, 2012; Chiaburu \& Marinova, 2005; Grossman \& Salas, 2011). Motivation is especially relevant for the quality of learning activities (e.g., Boekaerts \& Niemivirta, 2000; Pintrich, 2004; Wolters, 2003). Thus, an important research avenue is to investigate differences in individual learning engagement (and, in turn, learning gains), and the role of academics' motivations. Through understanding this, professional training courses can be designed to better support academics and facilitate productive learning experiences.

Achievement Goal Theory (AGT) is a prominent motivational theory that has been used to explain differences in learning processes and outcomes in achievement contexts. Achievement goals act as a motivational basis for the interpretation of learning situations and self-regulation therein, the quality of cognitive learning processes, and how these are experienced (cf. Butler, 2000; Maehr \& Zusho, 2009; Pintrich, 2000). In studies involving students, school teachers, and first investigations of university academics, achievement goal preferences have been related to aspects of professional learning (e.g., Daumiller, Dickhäuser, \& Dresel, 2019; Nitsche, Dickhäuser, Fasching, 
\& Dresel, 2013; Payne, Youngcourt, \& Beaubien, 2007; Senko, Hulleman, \& Harackiewicz, 2011). Most studies examining achievement goals for learning considered overall learning gains as a distal variable, while neglecting the process leading to these gains. Considering the learning process, individuals' engagement is an important variable leading to learning gains (Schmitz \& Wiese, 2006; Zimmerman, 2000). However, little is known about how goals affect academics' learning engagement and learning gains, and due to contextual differences in the learning opportunities of students, school teachers, and academics, previous findings cannot be transferred to academics without further consideration (e.g., Che-Ha, Mavondo, \& Mohd-Said, 2014; DeShon \& Gillespie, 2005). This research gap is surprising, as for academics, successfully gaining knowledge from professional training is particularly valuable. As such, the purpose of the present study was to investigate the effects of academics' achievement goals for their learning engagement and learning gains in professional training courses.

\section{Differences in Academics' Learning Engagement}

Learners who adopt a more engaged approach to learning are more likely to have increased learning gains (Froiland \& Worrell, 2016; Kuh et al., 2008; Reyes, Brackett, \& Rivers, \& Salovey, 2012). An engaged learner is described by putting forth effort, learning intensely, not being afraid of making mistakes, using deep-processing cognitive strategies (such as elaboration), remaining persistent, and actively thinking about ways to apply concepts to practical situations (Chin \& Brown, 2000). This highlights the multi-faceted nature of learning engagement that needs to be acknowledged to adequately examine its antecedents and consequences (Bryson \& Hand, 2007; Fredricks et al., 2004).

Consequently, to encompass the breadth of academics' learning engagement, we distinguished the following six aspects: Effort relates to the level of determination put forth in understanding material (e.g., listening attentively, taking notes) and is related to effective learning (Salomon, 2009). Learning intensity describes how deeply the content is engaged with (i.e., understanding material in a controlled and intentional manner), and is linked to desirable learning outcomes (Carini, Kuh, \& Klein, 2006). Risk-taking involves actively pursuing in-class learning opportunities (e.g., asking questions, participating in discussions) despite the risk of potentially being incorrect. Elaboration refers to enhancing information to "clarify the relationship between information to-be- 
learned and related information" (Hamilton, 1997, p. 299) and is crucial for memorizing learning material. Implementation outlines the application of information to a practical context (e.g., considering how to implement material into teaching practices), which is characteristic of deeper learning (Chin \& Brown, 2000). Finally, persistence, involves the continuation of focused learning in spite of challenges. Overall, it is expected that academics who employ these aspects throughout professional training courses will have a more positive learning experience and higher learning gains.

Based on individual variability in learning strategies and engagement over time (cf. Vermetten, Lodewijks, \& Vermunt, 1999), academics likely differ in their learning engagement throughout professional training courses. Besides interindividual differences between different academics, substantial intraindividual variation within the academics themselves throughout the course can be expected. For example, while the overall amount of learning engagement can be considered as decisive for their learning gains, there may be academics who begin the course with high engagement, but become less engaged throughout the course. Similarly, there may be academics who continually increase their engagement throughout the course. Both aspects (average levels and trends of time) may be grounded in differences in academics' motivations, and understanding their variability and relatedness is crucial for designing professional training courses and supporting academics' learning therein.

\section{Academics' Achievement Goals and Their Relevance for Learning}

Achievement goals are cognitive representations of competence-related end states in achievement contexts that individuals strive to approach or avoid (Elliot, 2005; Hulleman, Schrager, Bodmann, \& Harackiewicz, 2010). Different affective, cognitive, and behavioral associations have been documented for preferences of different achievement goals in diverse populations, such as students, athletes, and school teachers (Hulleman et al., 2010; Payne et al., 2007). Recently, AGT has also been used to describe the motivations of university academics (Authors anonymized, 2018; Daumiller et al., 2019; Daumiller, Grassinger, Dickhäuser, \& Dresel, 2016; Janke \& Dickhäuser, 2018; Janke, Rudert, \& Daumiller, 2018). These studies documented that university scholars pursue achievement goals that are differentially associated with aspects of their cognition and behavior, including those relevant for their learning. The following four goal classes appear to be particularly important for academics' learning: 
Learning (approach) goals constitute an active striving towards the development and growth of competences and attainment of maximum potential (Elliot \& McGregor, 2001; Grant \& Dweck, 2003; Hulleman et al., 2010). These goals can be expected to be highly functional for effective learning. Indeed, first research on university academics indicated their relevance for positive attitudes towards help seeking (Daumiller et al., 2019). Nonetheless, little is known about their significance for learning engagement and learning gains. Drawing on studies about other (non-student) populations, favourable associations have been found with this goal class and learning strategies as well as learning gains (see meta-analysis by Payne et al., 2007). Concerning students, learning goals have been linked to learning engagement (in the form of elaboration, persistence, and effort; Bandalos, Finney, \& Geske, 2003; Diseth, 2011; Elliot \& McGregor, 2001; Elliot, McGregor, \& Gable, 1999; Wolters, Shirley, \& Pintrich, 1996). Consequently, for academics in professional training courses, we expected learning approach goals to be positively associated with increased learning engagement and learning gains.

Appearance approach goals describe a focus on appearing competent to others (see Elliot \& McGregor, 2001; Grant \& Dweck, 2003). To realize such goals, individuals may pursue learning opportunities to appear better than others (using shallower learning processes), as opposed to learning to develop a deeper understanding. Because of this mixed pattern (between increased, but less functional learning engagement), the positive and negative effects of pursuing such goals might cancel each other out on the overall level. This is reflected in empirical findings for performance approach goals ${ }^{1}$ such as in the meta-analysis of Payne et al. (2007) where no associations with learning gains were found despite increased learning (adaptive and maladaptive) processes (e.g., Harackiewicz, Barron, Tauer, Carter, \& Elliot, 2000; Senko \& Dawson, 2016). Moreover, performance approach goals have been positively associated with surface processing, persistence, and effort in students (Elliot et al., 1999). Thus, we expected academics' appearance approach goals to go along with increased effort and persistence in professional training courses, but had no expectations regarding the other aspects of learning engagement.

Appearance avoidance goals constitute a desire to avoid appearing incompetent to others (e.g., not having other academics notice one's potential lack of knowledge, etc.). This goal class combines two negative aspects (focus and valence). For individuals strongly pursuing such goals, detrimental effects for their learning can be expected. This has been documented in empirical studies, where performance avoidance 
goals were associated with reduced learning gains (Payne et al., 2007) and positively predicted maladaptive learning engagement of students, i.e., more surface processing and disorganization, and less deep processing (Diseth, 2011; Elliot et al., 1999; Elliot \& McGregor, 2001; Meyer, Turner, \& Spencer, 1997; Midgley \& Urdan, 1995). Thus, we expected academics' focus on appearance avoidance goals in professional training courses to be associated with reduced learning engagement and reduced learning gains.

Lastly, work avoidance goals describe a striving towards getting through the day with little effort (by minimizing resources used during professional training). Strong work avoidance goals can be expected to lead to reduced commitment and shallower learning. First empirical investigations support this notion in that for academics, work avoidance goals have been related to perceiving help seeking as threatening (Daumiller et al., 2019) and unfavorable associations with learning strategies in students (Nolen, 1988). We therefore expected academics' work avoidance goals to be detrimental by leading to reduced learning engagement and reduced learning gains.

Taken together, achievement goals of academics can be expected to be highly relevant for their learning engagement and learning gains in professional training courses. Specifically, their influence on learning gains can be expected to be transmitted by the aforementioned aspects of learning engagement. While theoretically plausible, such mediation effects are scarcely investigated in AGT research. The limited research that does exist has focused on undergraduate students and their academic performance as a dependent variable, finding varying results for particular aspects of learning engagement. Fenollar, Roman, and Cuestas (2010) and Greene, Miller, Crowson, Duke, and Akey (2004) found positive effects of mastery goals on performance that were mediated by deep learning and cognitive strategies. Regarding performance approach goals, Elliot et al. (1999) found an association of increased performance, mediated by persistence and effort. In contrast, disorganization and strategic learning strategies were reported to mediate the negative effects of performance-avoidance goals on performance (Diseth \& Kobbeltvedt, 2010; Elliot et al., 1999). While these findings support the notion that aspects of learning engagement mediate the effects of achievement goals on learning outcomes, more research is required. Specifically, multiple aspects of learning engagement should be considered, actual learning gains, as well as different populations (other than undergraduate students). Examining these processes will contribute to a better understanding of the mechanisms of achievement 
goals leading to learning gains, and knowledge about how academics' motivations contribute to favorable learning in professional training courses.

\section{Research Questions and Hypotheses}

The aim of the current study is to understand the role that academics' achievement goals have for their learning engagement and learning gains in professional training courses. We first focused on the differences in learning engagement by testing the following hypothesis:

(H1) Academics differ substantially intra- and inter-individually in their learning engagement throughout professional training courses.

Specifically, we expected statistically significant intraindividual variability in the aspects of learning engagement and strong differences between the academics. We also sought to exploratively investigate differences between academics in trends of their learning engagement over time.

Moreover, we wanted to investigate how these differences are explained by academics' achievement goals and proposed the following hypotheses for university academics' in professional training courses:

(H2) Learning approach goals are functional for learning engagement and learning gains, i.e., they are positively associated with effort, learning intensity, risktaking, elaboration, implementation, persistence, and learning gains.

(H3) Appearance approach goals are positively associated with effort, persistence, and learning gains.

(H4) Appearance avoidance goals are detrimental to learning engagement and learning gains, i.e., they are negatively associated with effort, learning intensity, risktaking, elaboration, implementation, persistence, and learning gains.

(H5) Work avoidance goals are detrimental to learning engagement and learning gains, i.e., they are negatively related to effort, learning intensity, risk-taking, elaboration, implementation, persistence, and learning gains.

Aside from these direct associations, we put forward clear expectations regarding the modes of action:

(H6) Achievement goals affect learning gains through (i.e., mediated by) academics' learning engagement. 


\section{Method}

\section{Procedure}

University academics were asked to answer a series of paper-and-pencil questionnaires before, throughout, and after professional training courses. Before the course, participants answered a baseline questionnaire (T1) including questions about their sociodemographic background and achievement goals, followed by three assessments throughout the course (T2, T3, T4; each presented approximately 2 hours apart) measuring their learning engagement, and finally, a post-survey regarding their learning gains (T5).

\section{Sample}

Participants included 48 German university academics ${ }^{2}$ (75\% female) with an average age of $29.9(S D=7.3)$ years. The participants attended $M=6.1(S D=4.1)$ professional training courses prior to the study and their average length of service as a university instructor was $6.4(S D=8.7)$ semesters. They were sampled from six different voluntary professional training courses.

\section{Measures}

\section{Achievement Goals}

We assessed achievement goals using the achievement goal scale for academics by Daumiller et al. (2019). With four items each, we measured learning approach goals (e.g., "my goal is to expand my professional and methodological knowledge as much as possible"; $\omega_{\mathrm{h}}=.95$ ), appearance approach goals (e.g., "I want to be perceived as competent"; $\omega_{\mathrm{h}}=.89$ ), appearance avoidance goals (e.g., "I want to avoid being perceived as incompetent"; $\left.\omega_{\mathrm{h}}=.92\right)$, and work avoidance goals (e.g., "it is my goal to have the least amount of work as possible"; $\left.\omega_{\mathrm{h}}=.90\right)$. All items were answered on a Likert-type scale ranging from 1 (do not agree at all) to 8 (agree completely).

\section{Learning Engagement Throughout the Professional Training Courses}

To facilitate short assessments with minimum disturbances throughout the courses, we used selective and face valid single items from established scales (one item for each of the six aspects of learning engagement). The stem for each item read "During the last learning session...". 
Effort was assessed using an item from Engelschalk, Steuer, and Dresel (2017): "I made a lot of effort to understand everything". An item from a scale by Daumiller and Dresel (2018) was applied to measure learning intensity: "I intensely dealt with the learning content". Risk taking to pursue in-class activities was measured by adapting a single item by Steuer (2014): “I didn't dare to say anything because I was worried that it might be wrong". Since this item is reversely formulated, it was recorded for the analyses that high values reflected that participants did not hold back from saying something. Elaboration was assessed with an item from Dresel and Haugwitz (2006): "I tried to find connections between the current learning topic and what I already know". A self-constructed item was used to measure the implementation of concepts learned in the course to the participants' everyday work contexts: "I have thought about in which situations in my everyday work contexts I can implement what I have just learned". Lastly, a single item from Wolters (2004) was used to measure persistence: "I worked persistently and in a focused manner". Each item was answered with an 8-point Likerttype scale ranging from 1 (strongly disagree) to 8 (strongly agree).

\section{Learning Gains}

Learning gains were measured using a subscale of the SEEQ (Marsh, 1982). We used the German translation of this scale (Authors, anonymized), capturing (subjective) learning gains with five items (e.g., "I have learned and understood the subject materials in this course"; $\left.\omega_{\mathrm{h}}=.91\right)$ that were answered on a Likert-type scale ranging from 1 (strongly disagree) to 5 (strongly agree).

\section{Analyses}

Analyses were conducted using Mplus (Muthén \& Muthén, 2017). Taking the possible non-normality of some scales into consideration, analyses were conducted with MLR as an estimator. To test our hypotheses, we conducted latent growth curve modeling and mediation analyses. All data and codes that support the findings of this study are provided in an open access repository (https://osf.io/wes86/?view_only=f67cbdfe07094e9c903b0ebda1360292)

\section{Latent Growth Curve Modeling of Learning Engagement Throughout the Courses}

For each of the aspects of learning engagement, we estimated latent growth curve models. First, we estimated the growth process for each of the constructs, i.e., their 
intercepts and slopes (and their variances). Subsequently, we regressed the intercept and slope of each growth process on each of the achievement goals from the baseline measure in separate ("bivariate") models.

\section{Mediation Analyses of Goals on Learning Gains via Learning Engagement}

Based on the results of the latent growth curve modeling, we only used the average levels of the engagement aspects throughout the course (by aggregating their values at T1, T2, and T3). For each aspect, we estimated a separate model, regressed it on the achievement goals, and estimated their effects on learning gains. We estimated indirect effects to test the mediation hypothesis.

\section{Results}

Preliminary Results and Inter- and Intraindividual Differences in Learning

\section{Engagement}

Investigating the means and standard deviations of the assessed constructs (see Table 1) documented strong learning and little work avoidance goals, and functional levels of learning engagement and learning gains, while all variables exhibited a large amount of inter-individual differences. Additionally, an investigation of the ICCs indicated that all aspects of learning engagement varied throughout the courses but contained large person-stable fractions.

\section{Latent Growth Curve Modeling on Learning Engagement Throughout the}

\section{Course and their Bivariate Associations with Achievement Goals}

Latent growth curve modeling indicated that throughout the course, implementation increased and persistence decreased, while for the other aspects of learning engagement, no trend over time could be detected (see Table 2). Besides this, the slope of the learning engagement aspects often contained little variance, implying negligible interindividual differences regarding temporal trends. Only for persistence did we find statistically significant differences over time.

Subsequently, we analyzed how the growth processes of the learning engagement aspects (i.e., their intercept and slope) were associated with the achievement goals. In line with the manifest correlations, we found learning approach goals to be adaptively related to the overall level of all aspects of learning engagement, 
and work avoidance goals to be negatively related to them, while appearance (approach and avoidance) goals were associated with increased effort. Besides the substantial associations between goals and the intercepts of learning engagement, we did not find statistically significant associations with their slopes (with the exception of learning approach goals, which were related to an increase in elaboration over time). Thus, we focused only on the general levels of learning engagement throughout the course (and not their temporal development) in the next analyses.

\section{Effects of Achievement Goals on Learning Engagement and Learning Gains}

We investigated the effect of achievement goals on learning gains, mediated through the assessed aspects of learning engagement.

Effort (Figure 1a) was positively predicted by appearance (approach and avoidance) goals, but did not mediate the effect of these goals on learning gains. The mediation was only found for work avoidance goals that negatively predicted learning gains. In contrast, learning goals had a direct positive influence on learning gains.

Regarding learning intensity (Figure 1b), both learning and work avoidance goals had a (positive resp. negative) effect on learning gains that was (partially resp. fully) mediated by the learning intensity.

Risk taking (Figure 1c) was negatively predicted by learning goals and appearance approach goals, and negatively predicted by appearance avoidance goals, however they did not exert a statistically significant influence on the academics' learning gains.

For elaboration (see Figure 1d), we found a negative effect of work avoidance goals, and a positive effect of learning goals and (surprisingly also) appearance avoidance goals. Additionally, all three goals influenced learning gains mediated by academics' elaboration.

Contrarily, implementation and persistence (see Figure 1e and 1f), were found to be mediators for the positive effect of learning goals on learning gains, while no statistically significant effects were evident for the other goals.

Overall, we found that a substantial amount of variance in participants' learning engagement and their learning gains were explained $\left(R^{2}=.17-.54\right)$ and that the effects found were in line with the bivariate correlations reported in Tables 1 and 2. 


\section{Discussion}

In the current study, we investigated the role of academics' achievement goals for their learning engagement and learning gains in professional training courses. We explored academics in an important, not often empirically addressed, context and examined the effects of goals on learning gains via multiple aspects of learning engagement. The strengths of the study include its longitudinal design, the explicit testing of mediation effects, the inclusion of multiple facets of learning engagement, and their ecologically valid assessments. Taken together, our findings highlight the importance of academics' achievement goals for their learning, with learning approach goals leading to more functional learning engagement and work avoidance goals leading to less functional learning engagement, and both in turn affecting the overall learning gains.

Our results indicated that academics mostly began professional training courses with rather favorable motivations, learned well, and had high learning gains. This is unsurprising, as university academics constitute a population required to undergo formal academic learning in primary, secondary, and tertiary education. Furthermore, academics who voluntarily choose to participate in professional training courses are expected to already be quite motivated (cf. Lian, 2014). Nonetheless, the substantial differences that we found between the academics in their goals and learning indicate room for improvement and possibilities for support. At the same time, it should be noted that these functional initial values imply that large effects between goals and learning can not be expected. Consequently, our findings likely underestimate the actual effects of academics' goals on learning in professional training courses (i.e., including also those academics who may not participate voluntarily).

Concerning learning engagement over the duration of the course, our expectations of substantial intraindividual variability were confirmed (Hypothesis 1). The differences between the academics were larger than the differences within, indicating that academics can be distinguished regarding their learning engagement and that the latter might be explained by personal aspects of individual academics (such as their achievement goals). Additionally, throughout the professional training courses, only persistence decreased over time, while no other aspects of learning engagement showed temporal trends. When interpreting this decrease in persistence, it should be noted that learners have equal or superior outcomes in terms of focus, stamina, and retention from shorter courses (e.g., Scott, 2003). As such, professional training courses 
for academics may profit from being created as parsimoniously as possible (with the most pertinent information in the beginning) and providing support for maintaining persistence throughout the course. As we also observed that other aspects of learning engagement remained high with little differences between academics, designing interventions to provide support at the start of courses may be adequate for improving learning outcomes.

Regarding the influence of learning goals for academics' learning engagement and learning gains (see Hypothesis 2), our expectations were confirmed. Our findings emphasize the importance of strong learning goals for effective learning (in line with previous studies, e.g., Bandalos, et al., 2003; Diseth, 2011; Elliot \& McGregor, 2001; Payne et al., 2007). Surprisingly, we found that learning goals were not relevant for effort. This may indicate that, at least within a given learning setting, learning goals are not necessarily associated with greater quantity of learning engagement, but rather greater quality. Since learning goals also had a strong effect on risk-taking, this highlights their importance for the quality of academics' personal and social engagement in learning activities within professional training courses.

For appearance approach goals (see Hypothesis 3), our expectations were only partially fulfilled. In line with previous research, we found that strong appearance approach goals led to more effort during the course (Elliot et al., 1999), however, we did not find effects for persistence and learning gains. One reason for this could be that persistence may not be adequate for demonstrating superiority to others (as it may not be noticed in formal learning settings), and would not constitute a valuable strategy for realizing appearance goals. Regarding the learning gains, the positive and negative effects of this goal class might have canceled each other out, resulting in no learning gains. Surprisingly, we found appearance approach goals to be positively related to risk taking, which might imply that risk-taking situations may be seen as an attractive opportunity to appear competent in front of others. Taken together, moderate appearance approach goals can therefore be considered as functional for certain aspects of the learning process. Future research should investigate different levels of this goal class in detail and include further aspects, such as actual levels of competence as possible antecedents or moderators to better understand appearance approach goal pursuit and its effects (cf. Elliot \& Church, 1997).

Concerning appearance avoidance goals (see Hypothesis 4), our predictions were not fulfilled. Only the negative association with risk taking supported our 
hypothesis and is in line with the reasoning that engaging in risk-taking behaviors could pose a threat to one's image. The other two associations (increased effort and increased elaboration) may be explained by the notion that for individuals focused on a positive image, putting forth effort may be a sensible strategy to realize one's appearance avoidance goals, since this might easily be observed by others. This may be especially true in professional training courses, where a negative impression could be created by an observable lack of effort. Likewise, the increased elaboration might be interpreted in a similar manner: Since the learning content in academics' professional training courses is often rather complex, participants might need to utilize deep cognitive processing strategies such as elaboration to a greater extent to avoid appearing incompetent.

Lastly, regarding work avoidance goals (see Hypothesis 5), our expectations were largely confirmed. The negative associations with effort, learning intensity, elaboration, and learning gains support are strongly in line with the nature of this goal class. Such a striving to "get by" with minimal effort can be expected to lead to lower learning engagement and less learning gains. However, we did not find these maladaptive effects for all aspects of learning engagement. The lacking associations with risk taking, implementation, and persistence might imply that work avoidance goal striving could primarily affect resource-intensive strategies, such as deep elaboration and intensity, while risk taking and implementation might require fewer resources and be of less concern. Despite this, work avoidance goals can still be considered as highly maladaptive for university academics attending professional training courses.

Concerning the relationship between achievement goals and learning gains via learning engagement, our supposed modes of actions were supported (Hypothesis 6). Our results coincide with previous research (Fenollar et al., 2010; Greene et al., 2004) and theory driven predictions that learning goals should promote constructive learning behaviors (e.g., deep learning strategies) and consequently positive learning outcomes, while work avoidance goals should have the opposite effects (e.g., Elliot \& Church, 1997). These findings extend previous research that was mainly based on undergraduate students and contribute to a better understanding of the underlying mechanisms. Moreover, our results imply that academics' achievement goals do not directly influence learning gains, but only through differences in their learning engagement (with the exception of risk-taking).

Aside from this, the differences in the effects between the different models on the aspects of learning engagement support the consideration of multiple facets of 
learning engagement (as reflected by the weak correlations between these aspects). This might be an important avenue for understanding appearance approach and avoidance goals that have less consistent result patterns. Additionally, we found clear and consistent effects for learning and work avoidance goals that also explained a significant amount of variance in the two outcome variables. Since we observed the greatest effects for learning goals, promoting this goal class can be considered to be especially important for the success of academics in professional training courses.

When interpreting these results, two main limitations should be considered. First, we had a relatively small sample size with the academics being recruited from only six professional training courses, which may have reduced the variability of some of the assessed aspects. Future research should expand this and include and control for relevant features of the courses (e.g., course format, composition of the attendants). Second, we used a self-report measure for learning gains. While the self-report approach is sensible for assessing affective and cognitive constructs, distortions of learning gains cannot be ruled out (although we used an established scale and university academics should, as experts in the field of learning, be able to assess their own learning). Future research might consider using actual knowledge tests for assessing learning gains (which was not feasible in the current study due to the number of different courses).

Despite these limitations, our findings allow for first practical implications. Learning goals in academics should be better supported to allow for more successful experiences in professional training courses, and work avoidance goals should be reduced. This may be facilitated through (1) directly influencing these goals (e.g., stressing the importance of learning, discussing the detrimental effects that work avoidance goals can have), and (2) supporting these goal striving processes (e.g., by an arrangement of contextual features). Since our study was, to the best of our knowledge, the first of its kind to investigate academics' achievement goals in professional training courses, more research is required. Specifically, we consider intervention research as an important direction for expanding our knowledge on the effects of academics' motivations and developing strategies that foster adaptive achievement goal pursuit and, in consequence, high quality learning experiences for academics in professional training courses. 


\section{References}

Amundsen, C. \& Wilson, M. (2012). Are we asking the right questions? Review of Educational Research, 82, 90-126. doi:10.3102/0034654312438409

Ates, G., \& Brechelmacher, A. (2013). Academic career paths. In U. Teichler, \& E. Höhle (Eds.), The work situation of the academic profession in Europe (pp. 1335). Dordrecht, Netherlands: Springer Netherlands. doi:10.1007/978-94-0075977-0_2

Bandalos, D., Finney, S., \& Geske, J. A. (2003). A model of statistics performance based on achievement goal theory. Journal of Educational Psychology, 95, 604616. doi:10.1037/0022-0663.95.3.604

Biggs, J., \& Tang, C. (2011). Teaching for quality learning at university. British Journal of Educational Technology, 43, 94-95. doi:10.1111/j.1467-8535.2012.01317_3.x

Boekaerts, M., \& Niemivirta, M. (2000). Self-regulated learning. In M. Boekaerts, P. Pintrich, \& M. Zeidner (Eds.), Handbook of Self-Regulation (pp. 417-450). San Diego, CA: Academic Press. doi:10.1016/b978-012109890-2/50042-1

Borko, H. (2004). Professional development and teacher learning. Educational Researcher, 33, 3-15. doi:10.3102/0013189X033008003

Bouwma-Gearhart, J. (2012). Research university STEM faculty members' motivation to engage in teaching professional development. Journal of Science Education and Technology, 21, 558-570. doi:10.1007/s10956-011-9346-8

Bryson, C., \& Hand, L. (2007). The role of engagement in inspiring teaching and learning. Innovations in Education and Teaching International, 44, 349-362. doi:10.1080/14703290701602748

Butler, R. (2000). What learners want to know. Intrinsic and Extrinsic Motivation. In C. Sansone \& J. Harackiewicz (Eds.), The search for optimal motivation and performance. (pp. 161-194). San Diego, CA: Academic Press. doi:10.1016/b978012619070-0/50029-5

Butler, R. (2007). Teachers' achievement goal orientations and associations with teachers' help-seeking. Journal of Educational Psychology, 99, 241-252. doi:10.1037/0022-0663.99.2.241

Butler, R. (2012). Striving to connect. Journal of Educational Psychology, 104, 726742. doi:10.1037/a0028613

Carini, R., Kuh, G., \& Klein, S. (2006). Student engagement and student learning. Research in Higher Education, 47, 1-32. doi:10.1007/s11162-005-8150-9 
Che-Ha, N., Mavondo, F., \& Mohd-Said, S. (2014). Performance or learning goal orientation: Implications for business performance. Journal of Business Research, 67, 2811-2820. doi:10.1016/j.jbusres.2012.08.002

Chiaburu, D., \& Marinova, S. (2005). What predicts skill transfer? International Journal of Training and Development, 9, 110-123. doi:10.1111/j.14682419.2005.00225.x

Chin, C., \& Brown, D. (2000). Learning in science. Journal of Research in Science Teaching, 37, 109-138. doi:10.1002/(SICI)1098-2736(200002)37:2<109::AIDTEA3>3.0.CO;2-7

Colquitt, J., LePine, J., \& Noe, R. (2000). Toward an integrative theory of training motivation. Journal of Applied Psychology, 85, 678-707. doi:10.1037//00219010.g5.5.678

Daumiller, M., Dickhäuser, O., \& Dresel, M. (2019). University instructors’ achievement goals for teaching. Journal of Educational Psychology, 111, 131148. doi:10.1037/edu0000271

Daumiller, M. Dresel, M. (2018). Supporting self-regulated learning with digital media using motivational regulation and metacognitive prompts. Journal of Experimental Education. Advanced online publication. doi:10/csd9.

Daumiller, M., Grassinger, R., Dickhäuser, O., \& Dresel, M. (2016). Structure and relationships of university instructors' achievement goals. Frontiers in Psychology, 7, 375. doi:10.3389/fpsyg.2016.00375

DeShon, R., \& Gillespie, J. (2005). A motivated action theory account of goal orientation. Journal of Applied Psychology, 90, 1096-1127. doi:10.1037/00219010.90.6.1096

Diseth, Å. (2011). Self-efficacy, goal orientations and learning strategies as mediators between preceding and subsequent academic achievement. Learning and Individual Differences, 21, 191-195. doi:10.1016/j.lindif.2011.01.003

Diseth, A., \& Kobbeltvedt, T. (2010). A mediation analysis of achievement motives, goals, learning strategies, and academic achievement. British Journal of Educational Psychology, 80, 671-687. doi:10.1348/000709910x492432

Dresel, M., \& Haugwitz, M. (2006). The relationship between cognitive abilities and self-regulated learning. High Ability Studies, 16, 201-218. doi:10.1080/13598130600618066 
Ebert-May, D., Derting, T., Hodder, J., Momsen, J., Long, T., \& Jardeleza, S. (2011). What we say is not what we do. BioScience, 61, 550-558.

doi:10.1525/bio.2011.61.7.9

Elliot, A. (2005). A conceptual history of the achievement goal construct. In A. Elliot \& C. Dweck (Eds.), Handbook of competence and motivation (pp. 52-72). New York, NY: Guildford.

Elliot, A., \& Church, M. (1997). A hierarchical model of approach and avoidance achievement motivation. Journal of Personality and Social Psychology, 72, 218232. doi:10.1037/0022-3514.72.1.218

Elliot, A., \& McGregor, H. (2001). A $2 \times 2$ achievement goal framework. Journal of Personality and Social Psychology, 80, 501-519. doi:10.1037/00223514.80.3.501

Elliot, A., McGregor, H., \& Gable, S. (1999). Achievement goals, study strategies, and exam performance. Journal of Educational Psychology, 91, 549-563. doi:10.1037/0022-0663.91.3.549

Engelschalk, T., Steuer, G., \& Dresel, M. (2017). Quantity and quality of motivational regulation among university students. Educational Psychology, 37, 1154-1170. doi:10.1080/01443410.2017.1322177

Fenollar, P., Roman, S., \& Cuestas, P. (2007). University students' academic performance. British Journal of Educational Psychology, 77, 873-891. doi:10.1348/000709907x189118

Fredricks, J. A., Blumenfeld, P., \& Paris, A. (2004). School Engagement. Review of Educational Research, 74, 59-109. doi:10.3102/00346543074001059

Froiland, J., \& Worrell, F. (2016). Intrinsic motivation, learning goals, engagement, and achievement in a diverse high school. Psychology in the Schools, 53, 321-336. doi:10.1002/pits.21901

Grant, H., \& Dweck, C. (2003). Clarifying achievement goals and their impact. Journal of Personality and Social Psychology, 85, 541-553. doi:10.1037/00223514.85.3.54.

Greene, B. A., Miller, R., Crowson, H., Duke, B., \& Akey, K. (2004). Predicting high school students' cognitive engagement and achievement. Contemporary Educational Psychology, 29, 462-482.

Grossman, R., \& Salas, E. (2011). The transfer of training. International Journal of Training and Development, 15, 103-120. doi:10.1111/j.1468-2419.2011.00373.x 
Hamilton, R. (1997). Effects of three types of elaboration on learning concepts from text. Contemporary Educational Psychology, 22, 299-318.

doi:10.1006/ceps.1997.0935

Harackiewicz, J., Barron, K., Tauer, J., Carter, S., \& Elliot, A. (2000). Short-term and long-term consequences of achievement goals. Journal of Educational Psychology, 92, 316-330. doi:10.1037/0022-0663.92.2.316

Hulleman, C., Schrager, S., Bodmann, S., \& Harackiewicz, J. (2010). A meta-analytic review of achievement goal measures. Psychological Bulletin, 136, 422-449. doi:10.1037/a0018947

Janke, S. \& Dickhäuser, O. (2018). A situated process model of vocational achievement goal striving within members of the academic staff at university. Motivation and Emotion, 42, 466-481. doi:10.1007/s11031-017-9657-z

Janke, S., Daumiller, M., \& Rudert, S. (2018). Dark pathways to achievement in science. Social Psychological and Personality Science. Advanced online publication. doi:10.1177/1948550618790227

Lian, X. (2014). Factors that motivate faculty to participate in professional development activities (Doctoral dissertation). Available from ProQuest (UMI No. $3581491)$.

Maehr, M., \& Zusho, A. (2009). Achievement goal theory. In K. R. Wentzel \& A. Wigfield (Eds.), Handbook of motivation at school (pp. 77-104). New York, NY: Routledge.

Marsh, H. (1982). SEEQ. British Journal of Educational Psychology, 52, 77-95. doi:10.1111/j.2044-8279.1982.tb02505.x

Meyer, D., Turner, J., \& Spencer, C. (1997). Challenge in a mathematics classroom. The Elementary School Journal, 97, 501-521. doi: 10.1086/461878

Midgley, C., \& Urdan, T. (1995). Predictors of middle school students' use of selfhandicapping strategies. The Journal of Early Adolescence, 15, 389-411. doi: $10.1177 / 0272431695015004001$

Mizell, H. (2010). Why Professional Development Matters. Oxford, Ohio: Leaning Forward.

Muthén, L., \& Muthén, B. (2017). Mplus (version 8.1) [Computer Software]. Los Angeles, CA: Muthén \& Muthén.

Nitsche, S., Dickhäuser, O., Fasching, M., \& Dresel, M. (2013). Teachers’ professional goal orientations. Learning and Individual Differences, 23, 272-278. 
Nolen, S. (1988). Reasons for studying. Cognition and Instruction, 5, 269-287. doi:10.1207/s 1532690xci0504_2

Payne, S., Youngcourt, S., \& Beaubien, J. (2007). A meta-analytic examination of the goal orientation nomological net. Journal of Applied Psychology, 92, 128-150. doi:10.1037/0021-9010.92.1.128

Pintrich, P. (2000). The role of goal orientation in self-regulated learning. In M. Boekaerts, P. Pintrich \& M. Zeidner (Eds.), Handbook of Self-regulation, pp. 451-502. San Diego, CA: Academic Press.

Pintrich, P. (2004). A conceptual framework for assessing motivation and self-regulated learning in college students. Educational Psychology Review, 16, 385-407. doi:10.1007/s10648-004-0006-X

Pintrich, P., \& de Groot, E. (1990). Motivational and self-regulated learning components of classroom academic performance. Journal of Educational Psychology, 82, 33-40. doi:10.1037/0022-0663.82.1.33

Reyes, M., Brackett, M.., Rivers, S., White, M., \& Salovey, P. (2012). Classroom emotional climate, student engagement, and academic achievement. Journal of Educational Psychology, 104, 700-712. http://dx.doi.org/10.1037/a0027268

Salomon, G. (2002). Not all programs are created equal. In G. Salomon (Ed.), Peace education (pp. 3-15) Mahwah, NJ: LEA.

Schmitz, B., \& Wiese, B. (2006). New perspectives for the evaluation of training sessions in self-regulated learning. Contemporary Educational Psychology, 31, 64-96. doi: 10.1016/j.cedpsych.2005.02.002

Scott, P. (2003). Attributes of high-quality intensive courses. New Directions for Adult and Continuing Education, 97, 29-38. doi:10.1002/ace.86

Senko, C. \& Dawson, B. (2016). Performance-approach goal effects depend on how they are defined. Journal of Educational Psychology, 109, 574-598. doi:10.1037/edu0000160

Senko, C., Hulleman, C., \& Harackiewicz, J. (2011). Achievement goal theory at the crossroads. Educational Psychologist, 46, 26-47. doi:10.1080/00461520.2011.538646

Steuer, G. (2014). Fehlerklima in der Klasse [Error climate in the classroom]. Wiesbaden, Germany: Springer VS. 
Sunal, D., Hodges,, Sunal, C., Whitaker, K., Freeman, L., Edwards, L., ... \& Odell, M. (2001). Teaching science in higher education. School Science and Mathematics, 101, 246-257. doi:10.1111/j.1949-8594.2001.tb18027.x

van Eekelen, I., Boshuizen, H., \& Vermunt, J. (2005). Self-regulation in higher education teacher learning. Higher Education, 50, 447-471. doi:10.1007/s10734004-6362-0

Vermetten, Y., Lodewijks, H., \& Vermunt, J. (1999). Consistency and variability of learning strategies in different university courses. Higher Education, 37, 1-21. doi:10.1023/A:1003573727713

Wolters, C. (2003). Understanding procrastination from a self-regulated learning perspective. Journal of Educational Psychology, 95, 179-187. doi:10.1037/00220663.95.1.179

Wolters, C. (2004). Advancing achievement goal theory. Journal of Educational Psychology, 96, 236-250. doi: 10.1037/0022-0663.96.2.236

Wolters, C., Shirley, L., \& Pintrich, P. (1996). The relation between goal orientation and students' motivational beliefs and self-regulated learning. Learning and Individual Differences, 8, 211-238. doi: 10.1016/S1041-6080(96)90015-1

Zimmerman, B. J. (2000). Self-efficacy. Contemporary Educational Psychology, 25, 82-91. doi:10.1006/ceps.1999.1016 


\section{Footnotes}

${ }^{1}$ Looking at the empirical evidence regarding appearance (approach or avoidance) goals, it should be considered that most investigations did not address appearance (approach or avoidance) goals sensu strictu, but usually performance (approach or avoidance) goals that (also or mainly) focus on normative aspects-i.e., strivings to outperform others or not wanting to be worse than others.

${ }^{2}$ One person participated twice, with regard to two different courses. Since the participants' answers were course-specific, we decided to keep this data in the dataset. However, we ran all analyses again, excluding the participants' answers concerning the second course, to ensure the robustness of our results. 
Table 1

Descriptive Statistics and Correlations of Achievement Goals, Aspects of Learning Engagement and Learning Gains

\begin{tabular}{|c|c|c|c|c|c|c|c|c|c|c|c|c|c|}
\hline & \multicolumn{3}{|c|}{ Descriptive statistics } & \multicolumn{10}{|c|}{ Manifest correlations } \\
\hline & $M$ & $S D$ & Skew & 1 & 2 & 3 & 4 & 5 & 6 & 7 & 8 & 9 & 10 \\
\hline \multicolumn{14}{|l|}{ Achievement goals (T1) } \\
\hline [1] Learning & 7.54 & 1.01 & -4.77 & & & & & & & & & & \\
\hline [2] Appearance approach & 4.27 & 1.77 & 0.03 & -.04 & & & & & & & & & \\
\hline [3] Appearance avoidance & 4.92 & 1.93 & -0.31 & .08 & .64 & & & & & & & & \\
\hline [4] Work avoidance & 2.13 & 1.39 & 1.23 & -.48 & .19 & .13 & & & & & & & \\
\hline \multicolumn{14}{|c|}{ Learning engagement (aggregated over T2, T3, and T4) } \\
\hline [5] Effort & 6.62 & 1.44 & -1.90 & .25 & .34 & .38 & -.29 & & & & & & \\
\hline [6] Intensity & 6.72 & 1.11 & -1.12 & .31 & .14 & .13 &.- .34 & .66 & & & & & \\
\hline [7] Risk-taking & 7.51 & 0.99 & -2.62 & .54 & .08 & -.18 &.- .43 & .22 & .27 & & & & \\
\hline [8] Elaboration & 7.06 & 0.97 & -0.80 & .42 & .08 & .26 & -.40 & .48 & .71 & .33 & & & \\
\hline [9] Implementation & 6.73 & 1.34 & -1.47 & .34 & -.08 & -.03 & -.20 & .24 & .36 & .37 & .60 & & \\
\hline [10] Persistence & 6.16 & 1.30 & -0.60 & .41 & .16 & .19 & -.29 & .63 & .87 & .30 & .67 & .36 & \\
\hline Learning gains (T5) & 4.49 & 0.67 & -1.85 & .35 & .05 & .15 & -.24 & .49 & .71 & .26 & .69 & .53 & .65 \\
\hline
\end{tabular}

Note. Theoretical range for achievement goals and learning engagement: 1-8, learning gains: $1-5$. All statistically significant correlations are presented in bold, with $|r|>.27: p<.05,|r|>.36: p<.01$, and $|r|>.48: p<.001$. 
Table 2

Descriptive Statistics of Learning Engagement Throughout the Courses and Bivariate Associations with Achievement Goals

\begin{tabular}{|c|c|c|c|c|c|c|c|c|c|c|c|c|c|c|c|}
\hline & \multicolumn{7}{|c|}{ Descriptive statistics } & \multicolumn{8}{|c|}{ Associations with achievement goals } \\
\hline & \multicolumn{5}{|c|}{ Intercept } & \multicolumn{2}{|c|}{ Slope } & \multicolumn{4}{|c|}{ Intercept } & \multicolumn{4}{|c|}{ Slope } \\
\hline & $M(\mathrm{~T} 2)$ & $M(\mathrm{~T} 3)$ & $M(\mathrm{~T} 4)$ & $\mathrm{ICC} 1$ & $\mathrm{ICC} 2$ & $M$ & Var & LEA & APA & APV & WAV & LEA & APA & APV & WAV \\
\hline Intensity & 6.85 & 6.66 & 6.64 & $.57 * * *$ & $.80 * * *$ & -.14 & $<.01$ & $.34 *$ & .16 & .15 & $-.40 * *$ & - & - & - & - \\
\hline Risk-taking & 7.64 & 7.45 & 7.47 & $.47 * * *$ & $.73 * * *$ & -.08 & $<.01$ & $.65^{* * *}$ & .08 & -.20 & $-.54 * * *$ & - & - & - & - \\
\hline Persistence & 6.40 & 6.09 & 6.00 & $.57 * * *$ & $.80 * * *$ & $-.24^{*}$ & $.71^{* *}$ & $.44 * * *$ & .17 & .24 & $-.32 * *$ & .06 & .16 & .09 & -.04 \\
\hline
\end{tabular}

Note. $\mathrm{LEA}=$ Learning goals, APA $=$ Appearance approach goals, APV = Appearance avoidance goals, WAV =Work avoidance goals.

Regressions with “_- c could not be run due to too little variance of the slope. *: $p<.05, * *: p<.01, * * *: p<.001$. 
Figure 1. Direct and indirect effects of achievement goals at the baseline (T1), on learning engagement throughout the course (average of the short assessments at T2, T3, T4), and on learning gains after the course (T5). Correlations between achievement goals are not shown for clarity. Indirect effects are provided in square brackets.

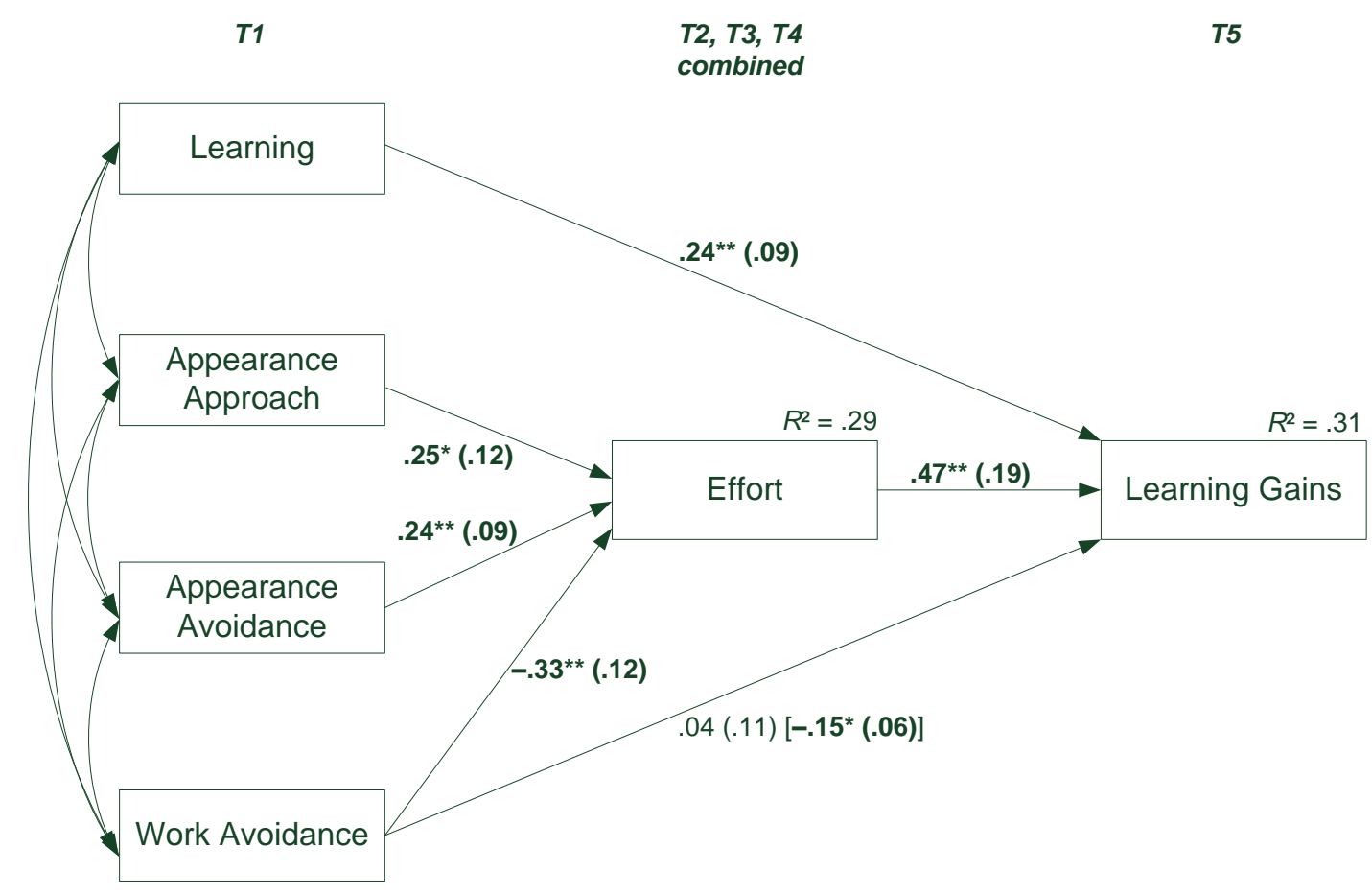

(a)

T1

T2, T3, T4

T5

combined

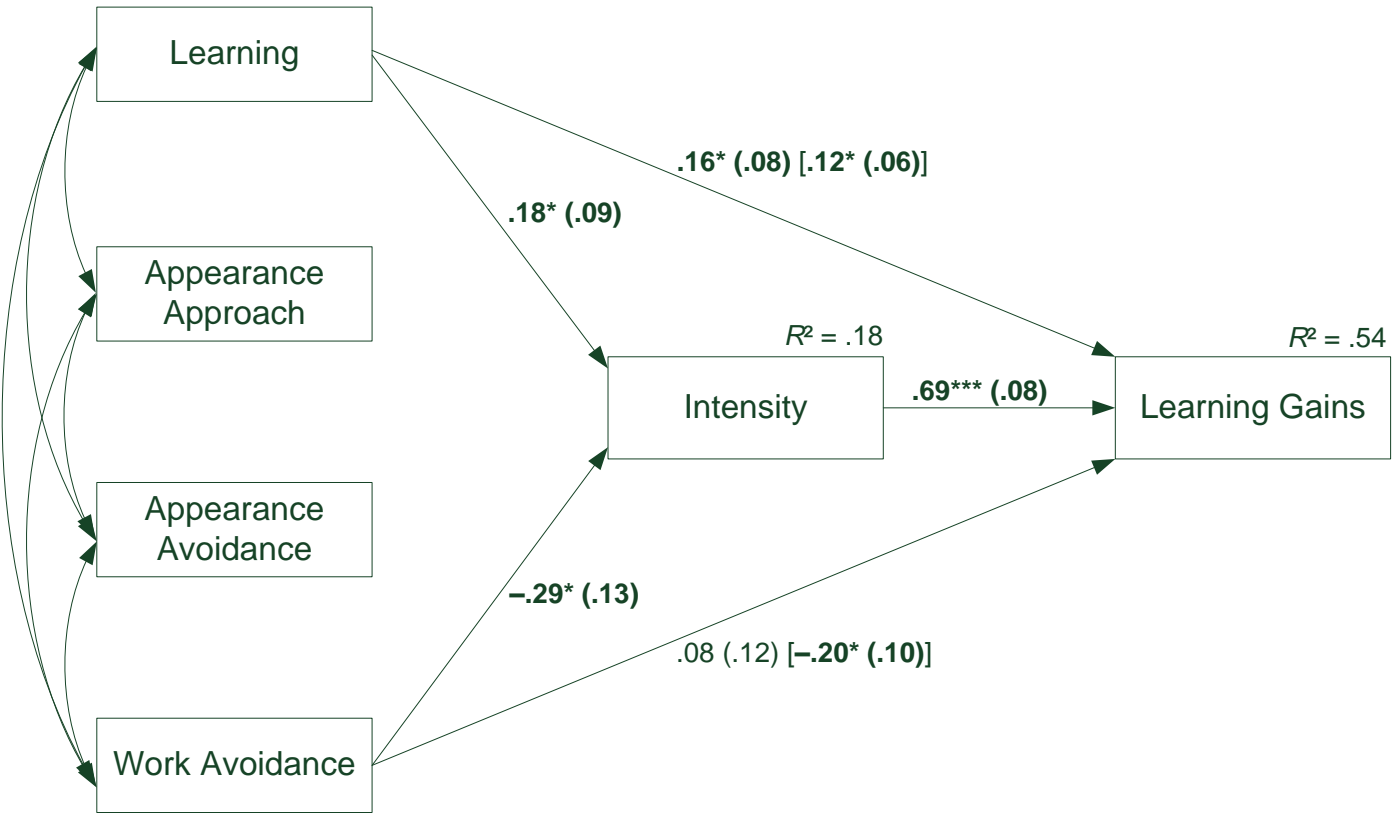

(b) 
Figure 1 (continued).

T1

$T 2, T 3, T 4$

combined

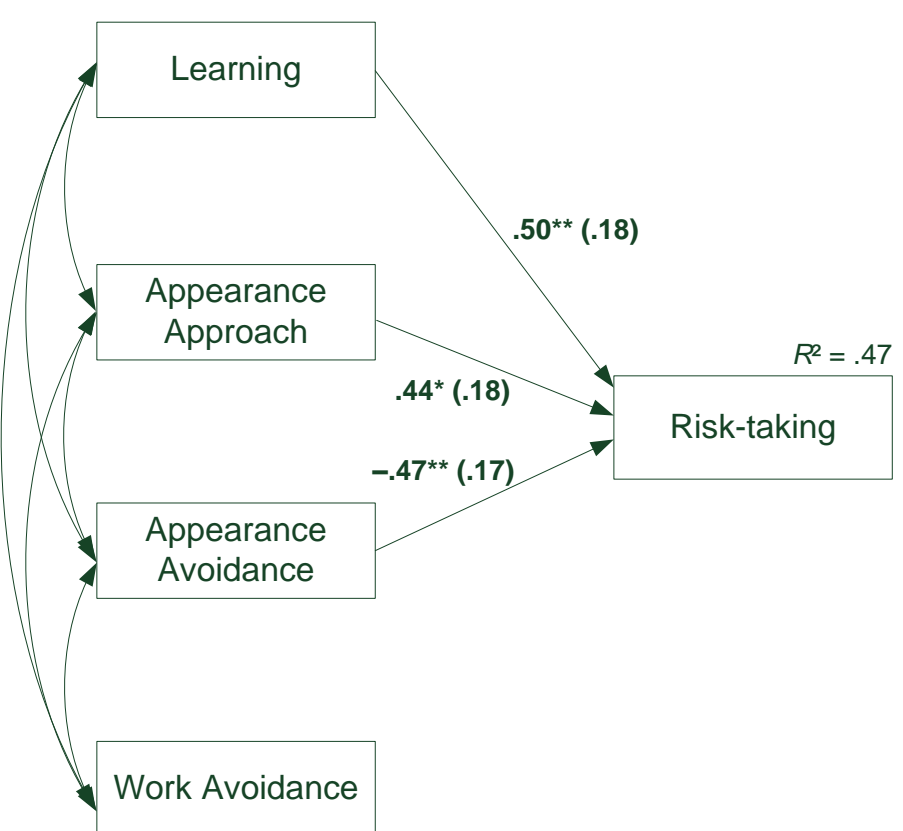

T5

(c)

T1

T2, T3, T4

combined

T5

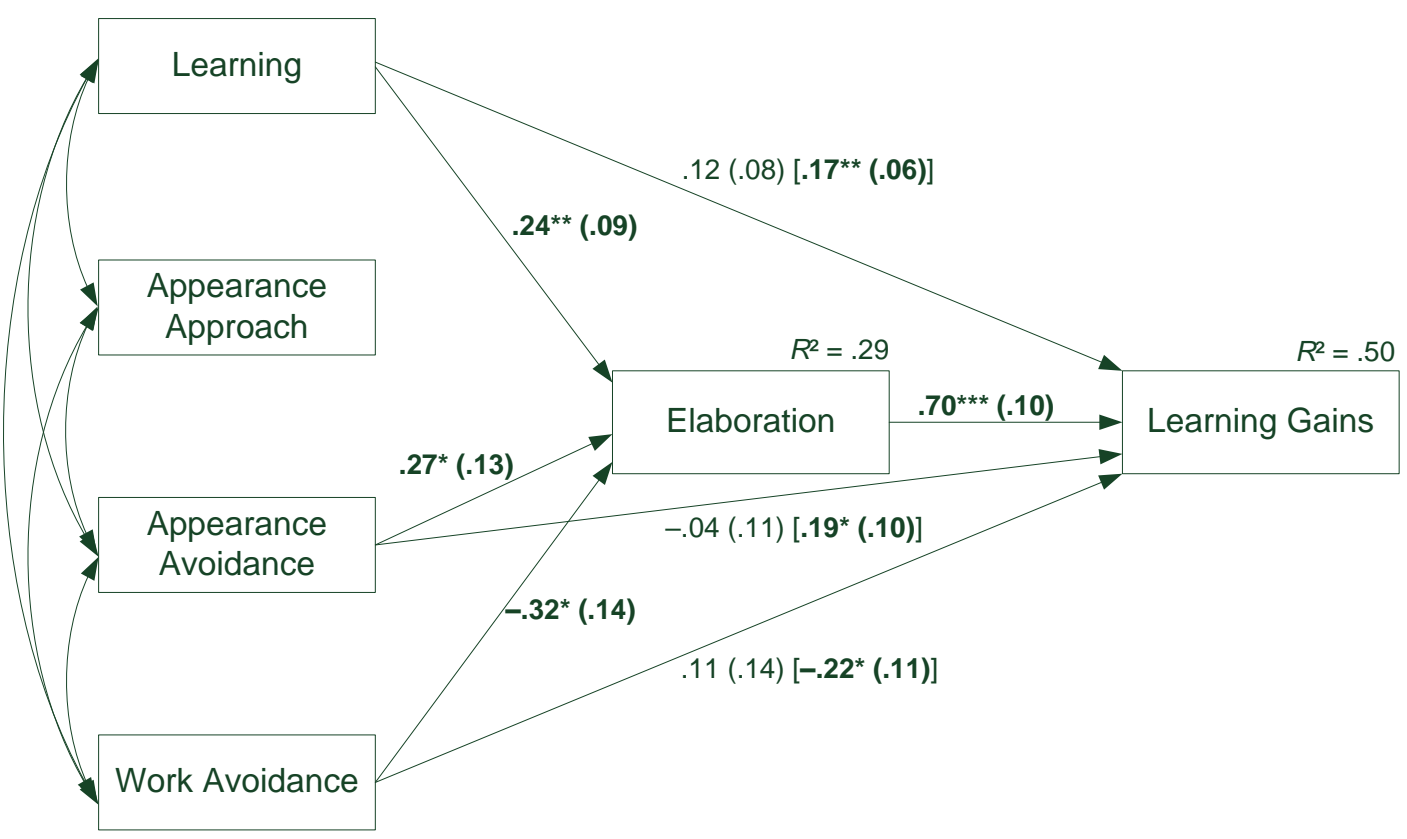

(d) 
Figure 1 (continued).

$T 1$

T2, T3, T4

T5

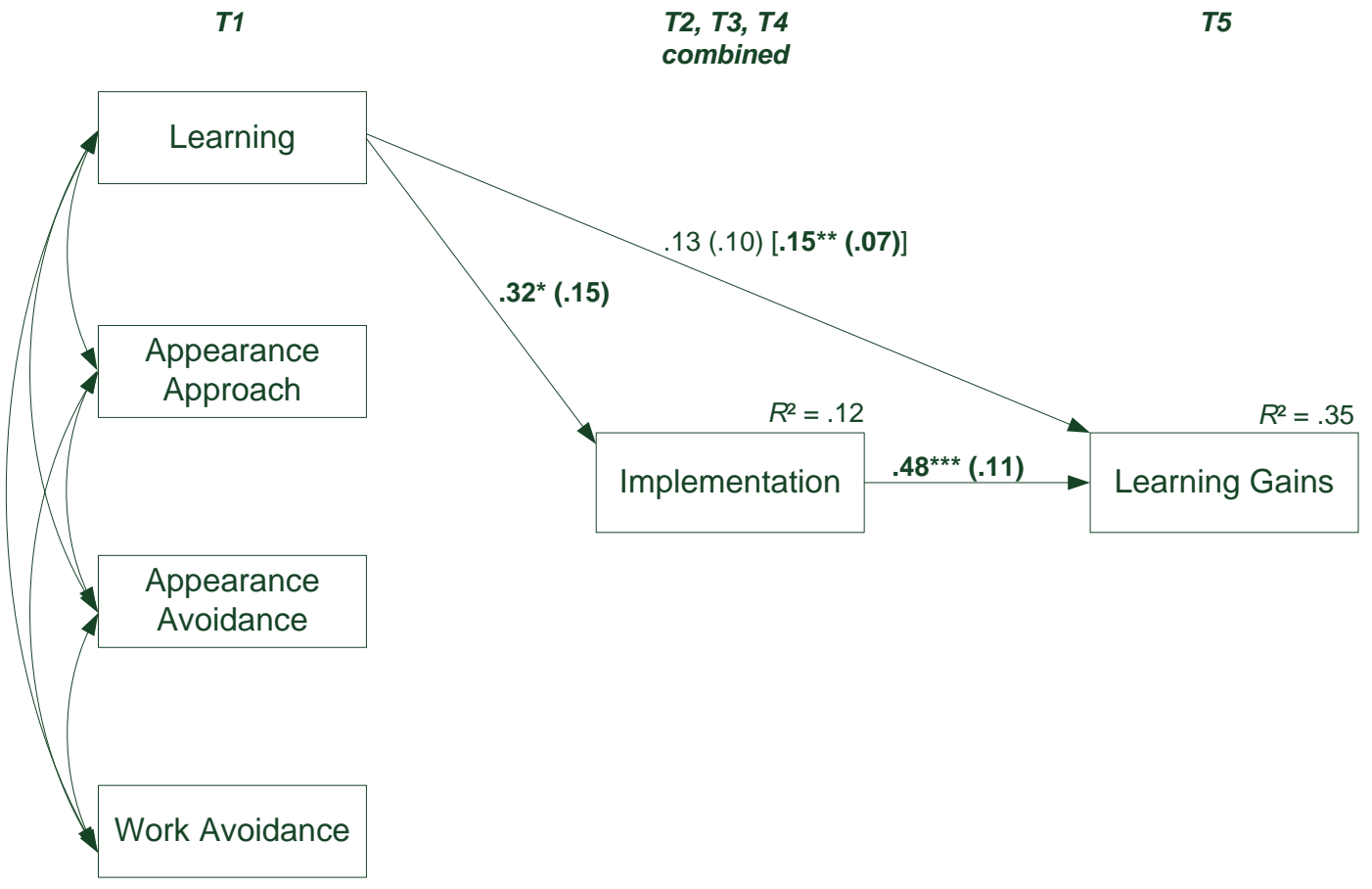

(e)

T1

T2, T3, T4

T5

combined

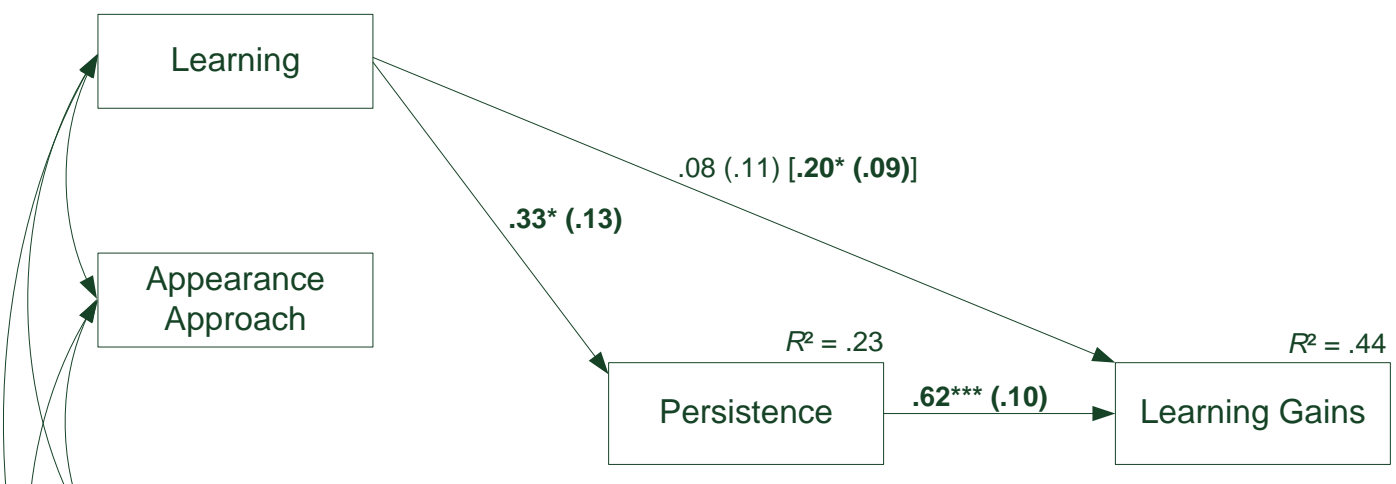

Appearance

Avoidance

Work Avoidance 